\title{
Study on Nutritional Supplements for Females in Dhaka City, Bangladesh
}

\author{
Sadia Zahin Tasfia ${ }^{1}$, Md. Alamgir Kabir ${ }^{2}$, Muhammad Rashedul Islam² and \\ Md. Elias-Al-Mamun ${ }^{2}$ \\ ${ }^{1}$ Department of Pharmacy, Faculty of Pharmacy, University of Dhaka, Dhaka-1000, Bangladesh \\ ${ }^{2}$ Department of Pharmaceutical Technology, Faculty of Pharmacy, University of Dhaka \\ Dhaka-1000, Bangladesh
}

(Received: January 19, 2020; Accepted: January 28, 2020; Published: January 30, 2020)

\begin{abstract}
Physiological problems due to deficiency of minerals and vitamins level in Bangladeshi female population are on the rise. The primary goal of this study was to find out the intake of nutritional supplements among urban female population. A survey on nutritional supplements was designed for females in some selected area of Dhaka city. One hundred fifty females were recruited, segmented under two sections (non-pregnant / pregnant) and most of them were interviewed face-to-face systematically. $10.7 \%$ of the sample was pregnant women and the rest $(89.3 \%)$ was the non-pregnant category. Participants were asked questions about their prescription drug patterns and intake of nutritional supplements. The study revealed that $53.0 \%$ of the female patients were not aware of the value of daily intake of nutritional foods. So, we also found that nutritional supplements were given to the patients continuously $(34.48 \%)$, occasionally $(18.39 \%)$ and at first $(28.74 \%)$. Calcium supplement (36.90\%), zinc supplement (14.10\%) and iron supplement (19.90\%) were prescribed most.
\end{abstract}

Keywords: Nutritional supplement, calcium, female, pregnant, prescription.

\section{Introduction}

Dietary supplement is generally a calculated planning to parallel the diet which contains mostly vitamins and minerals, and a lesser extent amino acids, herbs or fish oils. These are viewed as an important source of essential nutrients and providing a solution to daily deficit or help to prevent diseases and improving health condition. A number of factors such as age, gender, educational level, and socioeconomic condition, place of residence or accommodation, and ethnicity are involved. Micronutrient-related malnutrition is often termed as 'hidden hunger' because the consequences are not always visible (Mominul et al,. 2018).

Now a days mostly vitamins and minerals are used as dietary supplements by half to two-thirds of
American adults (Dickinson and Mackay, 2014). Different surveys show that nutritional supplement users adopt various positive health-related habits like better dietary patterns, excercising regularly and maintaining a healthy body weight (Bailey et al., 2011; Radimer et al., 2004). The situation of micronutrient deficiencies in Bangladesh is increased day by day. Previous study showed that one fourth of the population in Bangladesh at age 15 to $<49$ years were suffering from chronic energy deficiency or thinness (BMI $<18.5$ ) and about $25 \%$ of adult were undernourished or thin (BMI <18.5) at aged $46-<60$ years in Bangladesh. (Karim and Tasnim, 2015).

The food system in Bangladesh is rapidly changing (Zahirul et al., 2014). Changes are taking place in the patterns of consumption and expenditure

Correspondence author: Muhammad Rashedul Islam; E-mail: rashed1505@yahoo.com

DOI: https://doi.org/10.3329/bpj.v23i1.45318 
in urban and rural areas in terms of: (i) market purchases versus own production; (ii) the commodity base of diets; (iii) a long term tendency towards a growing role of international trade in food commodities, and hence greater influence of trade policies and international prices on domestic prices and (iv) more processing of food commodities outside the immediate producing or consuming households. (Owens et al., 2014; Ahmed et al., 2000). Women are more likely to suffer from nutritional deficiencies than men are, for reasons including women 's reproductive biology, low social status, poverty, and lack of education (Prentice et al., 1996). Socio cultural traditions and disparities in household work patterns can also increase women's chances of being malnourished (Shafique et al., 2007).

The objective of the present study is to find out the nutritional supplement prescribing pattern of female population in some selected areas of Dhaka city. A combination of prescription audit and feedback has been shown to be a successful technique which improves the quality of prescribing. (Suliga, 2015). So, the survey was designed and conducted systemically to dig up the current scenario and habits of prescriber's about female health and the necessity of precise nutritional supplement.

\section{Methodology}

Study design: This was a field survey which was conducted by semi-structured questionnaire. method. In this study, data were collected from 150 female outward patients from different locations (Dhaka Medical College, Women's Medical College and Hospital and Bangladesh Medical college) throughout the Dhaka city. The study was carried out between a period of January 01 to March 31, 2019.

Participant's information: Participants (age between 16-70 years old) were recruited from selected hospitals in metropolitan Dhaka city randomly and the participation was on voluntary basis. A questionnaire was developed on the basis nutritional supplement consumption and lifestyle .The questionnaire was self-administered to all the participants, who answered it anonymously.

Survey form:

\begin{tabular}{|c|c|}
\hline \multicolumn{2}{|r|}{$\begin{array}{l}\text { A short survey on Nutritional Supplements of female population in some } \\
\text { selected area of Dhaka city. }\end{array}$} \\
\hline \\
\hline \multicolumn{2}{|r|}{ Location : ........... Patients Name $: \ldots \ldots \ldots$} \\
\hline \multicolumn{2}{|c|}{$:$} \\
\hline SL & Questionnaire \\
\hline Q-1 & $\begin{array}{l}\text { Are you pregnant? } \\
\quad \square \text { Yes } \square \text { No } \\
\text { If yes, how many weeks pregnant are you? } \\
\text { Ans : ........... Weeks }\end{array}$ \\
\hline Q-2 & $\begin{array}{l}\text { How old are you? } \\
\text { Ans : ................... }\end{array}$ \\
\hline Q-3 & $\begin{array}{l}\text { What is your occupation? } \\
\text { Ans: .................... }\end{array}$ \\
\hline$Q-4$ & 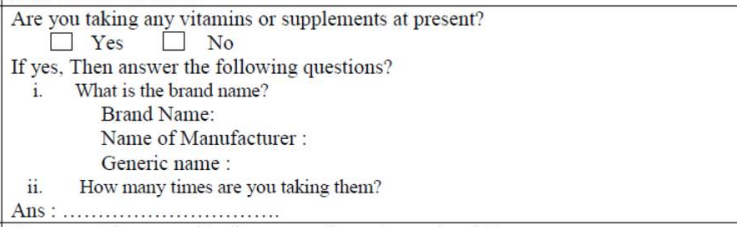 \\
\hline Q-5 & $\begin{array}{l}\text { Have you taken any vitamins or supplements previously? } \\
\quad \square \text { Yes } \square \text { No } \\
\text { If yes, for how many days? } \\
\text { Comments:..................... }\end{array}$ \\
\hline Q-6 & $\begin{array}{l}\text { What is your family income? } \\
\text { Ans: ................. }\end{array}$ \\
\hline Q-7 & $\begin{array}{l}\text { Do you eat meat, chicken, fish, eggs, green leafy vegetables daily? } \\
\square \text { Yes } \square \text { No }\end{array}$ \\
\hline
\end{tabular}


Statistical analysis: The data collected from the survey was tabulated, analyzed and graphically presented using Microsoft Office Excel 2016.

\section{Results and Discussion}

The study was conducted on the urban physician's tendency to prescribe nutritional supplement among female patients of Dhaka city in Bangladesh with a standard structured questionnaire. In the present work, it observed that a great portion of study female population (89.3\%) is non-pregnant. In case of occupation, $15.3 \%$ patients were student, $64.7 \%$ were housewife and $20.0 \%$ were working women. The number of pregnant women is $10.7 \%$. It was also revealed that the most prevalent age group of the participants $(44.7 \%)$ is $26-40$ years, $34 \%$ were between 12-25 years, $18.6 \%$ were between 41-55 years and $2.7 \%$ were above 55 years as shown in table 1.

We also assessed between their prescription (presence of nutritional supplements in 58\% prescriptions) and the knowledge or alertness of the participants for daily intake of nutritional food and their frequency. It observed that a major portion of the female patients $(53.0 \%)$ were not aware of the value of daily intake of nutritional foods. From the sensible $(33.00 \%)$ group, the daily consumption of nutritional foods (meat, eggs, milk, leafy vegetables, fruits etc.) was highly satisfactory in $26 \%$ patients whereas the negligible faction is $32.0 \%$ (Table 2).

Table 1. Demographic characteristics of study population.

\begin{tabular}{lccc}
\hline Question pattern & Response pattern & Frequency $(\mathrm{N}=150)$ & Percentage (\%) \\
\hline \multirow{3}{*}{ Age } & $12-25$ & 51 & 34.0 \\
& $26-40$ & 67 & 44.7 \\
\multirow{3}{*}{ Category } & $41-55$ & 28 & 18.6 \\
& $56-70$ & 4 & 2.7 \\
Occupation & Pregnant & 16 & 10.7 \\
& Non-Pregnant & 134 & 89.3 \\
& Housewife & 97 & 64.7 \\
& Working women & 30 & 20.0 \\
\hline
\end{tabular}

Table 2. Perception about daily intake of nutritional foods.

\begin{tabular}{lccc}
\hline Question pattern & Response pattern & Frequency (N=150) & Percentage (\%) \\
\hline \multirow{2}{*}{ Knowledge } & Conscious & 79 & 53.0 \\
& Unaware & 50 & 33.0 \\
Daily consumption of & didn't answer & 21 & 14.0 \\
nutritional foods & Highly satisfactory & 13 & 26.0 \\
(N=50) & Satisfactory & 21 & 42.0 \\
& Negligible & 16 & 32.0 \\
Nutritional supplements & Yes & 87 & 58.0 \\
exposure in prescription & & 63 & 42.0 \\
& No & & \\
\hline
\end{tabular}


From the prescription coverage, it was found that dietary supplement was always given to $34.48 \%$ patients, $18.39 \%$ were given occasionally and 28.74 $\%$ were given for the first time. In 87 prescriptions out of 150, doctors usually prescribed calcium supplement for majority of the patients $(36.90 \%)$ Zinc supplement was prescribed for $14.10 \%$ patients whereas iron supplement among $19.9 \%$ patients. Different combinations of multivitamins have their percentage of $29.10 \%$ patients (Table 3 ).

Table 3. Prescription status of nutritional supplement among study population.

\begin{tabular}{llcc}
\hline Question pattern & Response pattern & Frequency $(\mathrm{N}=87)$ & Percentage $(\%)$ \\
\hline \multirow{5}{*}{ Frequency } & Always & 30 & 34.48 \\
& Occasionally & 16 & 18.39 \\
& First time & 25 & 28.74 \\
& Unaware of previous & 16 & 18.39 \\
Preference & prescription history & & \\
& Calcium & 33 & 36.90 \\
& Iron & 17 & 19.90 \\
& Zinc & 13 & 14.10 \\
& Other multivitamins & 24 & 29.10 \\
\hline
\end{tabular}

\section{Conclusion}

The use of nutritional supplements among female populations is popular worldwide. In conclusion, this study expands the existing scenerios regarding prescription pattern of urban female of different age groups. Our study also has some limitations. We took samples from only three medical institutions of Dhaka city and therefore caution should be taken to generalize the data for nationwide female populations. However, it is currently unclear whether physicians perform necessary physiological tests to identify vitamin D/calcium/iron level of the patients and if this influenced them to prescribe a dietary supplement. It is important for us as a society to raise awareness about the health issue of female society. We should study more to find out the root causes behind dietary supplement use,

\section{References}

Ahmed, S., Adams, A., Chowdhury, M. and Bhuiya, A. 2000. Gender, socioeconomic development and healthseeking behavior in Bangladesh. Soc. Sci. Med. 51, 361-371.
Bailey, R.L., Gahche, J.J., Lentino, C.V., Dwyer, J.T., Engel, J.S., Thomas, P.R., Betz, J.M., Sempos, C.T.and Picciano, M.F.2011. Dietary supplement use in the United States, 2003-2006. J. Nutr. 141, 261266.

Karim, K. and Tasnim, T. 2015. Nutritional status, dietary food and nutrient consumption patterns in monga affected area of the northern part of Bangladesh. Asian. J. Clin. Nutr, 7, 55-63.

Mominul, I., Md., T. H., Md., S. Al-F., Md. A. M., Biplob, K. B., Arafat, H. R. and Rajib, K. R. 2018. Dietary Supplements Use and Associated Determinants Among Adult Population in Southern Bangladesh. Am. J. F. Sci. Nut. Res.. 5, $64-70$

Owens, C., Toone, T. and Steed-Ivie, M. 2014. A survey of dietary supplement knowledge, attitudes and use in a rural population. J. Nutr. Food. Sci. 4, 304-309.

Prentice, A.M., Spaaij, C.J.K., Goldberg, G.R., Poppitt, S.D., van Raaij, J.M.A., Totton, M., Swann, D. and Black, A.E. 1996. Energy requirements of pregnant and lactating women. Eur. J. Clin. Nutr. 50, 82-111. 
Radimer, K., Bindewald, B., Hughes, J., Ervin, B., Swanson, C. and Picciano, M.F. 2004. Dietary supplement use by US adults: data from the National Health and Nutrition examination survey, 1999-2000. Am. J. Epidemiol. 160, 339-349.

Shafique, S., Akhter, N. Stallkamp, G., de Pee, S., Panagides, D. and Bloem, M.W. 2007. Trends of under- and overweight among rural and urban poor women indicate the double burden of malnutrition in Bangladesh. Int. J. Epidemiol. 36, 449-457.
Suliga E. 2015. Nutritional behaviours of pregnant women in rural and urban environments. Ann. Agric. Environ. Med. 22, 513-517.

Zahirul, I., Mohamamd, A. and Chirstel, L.A. 2014. Nutritional status of women in Bangladesh: comparison of energy intake and nutritional status of a low income rural group with a high income urban group. Asia. Paciifc. J. Clin. Nutr. 13, 61-68. 